$\mathbb{T}$ periodica polytechnica

Mechanical Engineering

$53 / 1(2009) 3340$

doi: 10.3311/pp.me.2009-1.05

web: http://www.pp.bme.hu/me

(c) Periodica Polytechnica 2009

RESEARCH ARTICLE

\section{Aerodynamic study on straight, arc-swept and twisted stationary linear cascade blades}

\author{
Gergely Rábai / János Vad
}

Received 2007-10-10, accepted 2008-01-21

\begin{abstract}
A computational investigation has been carried out on the effects of sweep and twist in stationary linear cascades. Circular arc sweep has been applied to the datum cascade of straight cylindrical blades, i.e. spanwise constant stacking line curvature was prescribed. Positive sweep was applied near the endwalls, and the sweep angle distribution was symmetrical to the midspan plane. The straight and the arc-swept blades were studied at low, near-design, and high incidence angles of the straight blading. Twisted versions of the straight and the arcswept blades were studied for spanwise constant inlet flow angle. The studies demonstrated the benefits of circular arc sweep for both untwisted and twisted blade rows, such as local loss reduction and uniformisation of cascade outlet axial velocity profile. Blade twist was found favourable from the aspect of endwall separation zone reduction.
\end{abstract}

\section{Keywords}

axial flow turbomachinery $\cdot$ stationary linear cascades $\cdot$ computational fluid dynamics · validation · sweep · spanwise changing blade circulation

\section{Acknowledgement}

This work has been supported by the Hungarian National Fund for Science and Research (OTKA) under contracts No. T 043493, T 037651, and K63704; and, on behalf of J. Vad, out of the István Széchenyi Fellowship under contract No. SZÖ 271/2003.

\section{Gergely Rábai \\ János Vad}

Department of Fluid Mechanics, BME, H-1111 Budapest, Bertalan Lajos utca 4-6, Hungary

\section{Introduction}

In order to study fluid mechanical phenomena in decelerating cascades of axial flow turbomachinery, investigation on stationary linear cascades (SLC) instead of realistic annular stator and rotor blade rows appears as a widely accepted modelling simplification, e.g. [1]. This simplification is widespread in the survey of effects of blade sweep [2-4]. An axial flow turbomachinery blade is considered herein to be swept, when each blade section of a datum blade of stacking line normal to the endwall is displaced parallel to the chord in a prescribed manner. Blade sweep offers a potential for improvement of turbomachinery stage performance and efficiency, increase of pressure peak, shift of stall margin towards lower flow rate [5, 6], reduction of shock losses [7], and noise reduction [8].

All of the studies reported on SLC with sweep are confined to blades with spanwise constant stagger angle, corresponding to a spanwise nearly constant incidence angle. Nevertheless, the incidence angle often varies along the blade span. This may be due to off-design operation or due to the simplifications in blade design and manufacturing (e.g. industrial axial fans of spanwise constant stagger angle).

The above yield that blade sweep and spanwise changing incidence often characterize the axial flow blade rows simultaneously. This paper aims at satisfying the need of studying sweep, spanwise changing incidence, and their combination in SLC, by means of computational fluid dynamics (CFD). A sweeping style called circular arc sweep has been applied to non-twisted and twisted datum blade rows, and the cascades were investigated over a wide incidence range.

\subsection{Definition of case study cascades}

The cascades of present case study have blades of the controlled diffusion profile described in [3]. The blades are bounded by endwalls with no clearance. The straight (unswept, untwisted) cylindrical datum blading is the one denoted as STR in the previous reference. A sketch of the coordinate system and the characteristic angles are presented in Fig. 1

Table 1 presents the main geometrical and operational data of STR. The inlet Reynolds number is based on the inlet velocity, 
Tab. 1. Cascade geometrical and operational data for STR

\begin{tabular}{ll}
\hline Stagger angle $\gamma$ & $14.4 \mathrm{deg}$ \\
\hline Solidity $c / s$ (spanwise constant chord) & 1.67 \\
\hline Aspect ratio $S / c$ & 1.27 \\
\hline Inlet Reynolds number & 350.000 \\
\hline Inlet Mach number & 0.15 \\
\hline
\end{tabular}

the blade chord and the kinematic viscosity of air at $20{ }^{\circ} \mathrm{C}$. The flow is considered incompressible, on the basis of the inlet Mach number computed for air at $20{ }^{\circ} \mathrm{C}$. The STR blading has been tested for inlet flow angles $\alpha_{1}=27 \mathrm{deg}$ (termed herein as "low" incidence), $36 \mathrm{deg}$ (the near-design incidence of STR), and 45 deg (termed herein as "high" incidence). These operating states are denoted as STR27, STR36 and STR45, respectively.

Various views of the case study blades discussed herein, together with the related coordinate frames, are illustrated in Fig. 2. Sweep has been applied to the straight datum blading, retaining spanwise constant stagger. Since the presence of stacking line blend points leads to local uploading of the blade [3, 9] and this may result in increased losses [10], the authors intended to avoid any stacking line blend points along the entire span in the design of the case study blades. Since a blend point represents spanwise changing curvature of the stacking line, spanwise constant stacking line curvature was demanded for the swept blades. Prescribing sweep angles at the endwalls, this condition results in a circular arc-shaped stacking line. The resultant "arc-swept" blading is denoted herein as ASW. Similar sweeping style, although confined to the leading edge (LE), has been applied to the stator blades in [11]. The sickle-shaped blades of the "G-fan" in [8] and of the automotive cooling fan in [12] also have an appearance similar to that of the "arc-swept" blades. They appear to be free from characteristic blend points, even though the stacking line curvature varies slightly along the span.

The following definitions are applied, based on [13]. Sweep is said to be positive near the endwall when a blade section under consideration is upstream of the adjacent inboard section. Dihedral is said to be positive or negative when the endwall makes an obtuse or an acute angle with the suction side (SS), respectively. The blading with positive sweep of $30 \mathrm{deg}$ angle (measured from the line normal to the endwall) was found to be successful in reduction of endwall losses by [3], and the present CFD method was also validated experimentally for this blading. Therefore, a positive sweep of $30 \mathrm{deg}$ angle was prescribed at both endwalls for ASW, although this sweep configuration is not necessarily considered as the most favourable one.

The ASW blade row was tested for inlet flow angles applied for STR, i.e. ASW27, ASW36, and ASW45 cases were studied.

By changing the stagger angle along the span of the straight datum blading (by rotating the blade section profiles around the profile thickness halving point at mid-chord), a twisted, unswept case study cascade, denoted as TWD, has been generated. The original stagger angle was retained at the endwall being closer to the $x-y$ plane (see Fig. 2), and spanwise linearly changing twist was applied toward the other endwall, reducing the stagger linearly along the $z$ axis, with maximum twist angle of $18 \mathrm{deg}$. For the TWD tests, $\alpha_{1}=27 \mathrm{deg}$ inlet flow angle was set. This resulted in incidence corresponding to $27 \mathrm{deg}$ inlet flow angle at one endwall (of original stagger), $36 \mathrm{deg}$ inlet flow angle at midspan, and $45 \mathrm{deg}$ inlet flow angle at the other endwall. Therefore, the behaviour of flow at the endwalls and at midspan of the twisted blading is comparable with the STR and ASW tests of the corresponding inlet flow angles. By sweeping TWD with spanwise sweep angle distribution identical with that of ASW, a twisted-swept blading, denoted herein as TWS, has been generated. TWS was tested for the same inflow condition as applied to TWD.

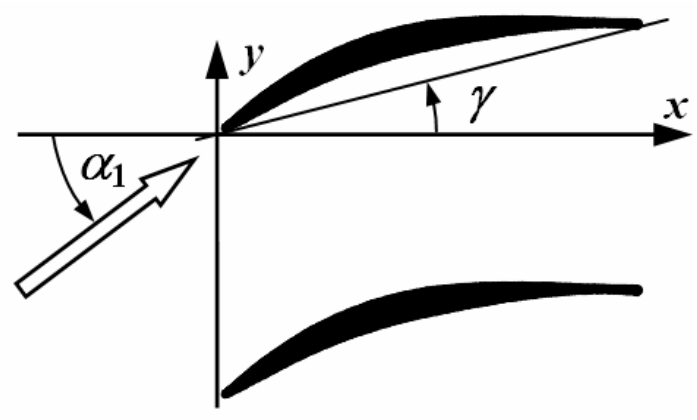

Fig. 1. Characteristic angles

\section{CFD Technique and validation}

The applied CFD technique and validation has been documented in [14] and in [15], so only a brief account is given here. As e.g. in [16] and [17], the present paper is based on computational case studies carried out with use of the commercially available finite-volume CFD code FLUENT (Version 6.1, 2003).

The turbulence model elaborated by Spalart and Allmaras [18] has been used, being accepted in advanced design systems of turbomachinery with swept blades [19,20] also involved FLUENT computations utilising the Spalart-Allmaras model in studies of axial flow cascades, at a fixed representative blade Reynolds number of 200.000 , being in the same order of magnitude with the Reynolds number valid for the studies presented herein (see Table 1). The authors are currently working on introduction of a transition model for future investigation of sweep and lean effects on a general platform. For the particular cases discussed herein, as measurements by Sanger and Shreeve [21] and also computations by the authors indicate, the investigated blade profile shows characteristic LE laminar separation even at lower incidences, probably due to the cylindrical LE. This results in separation induced transition already near the point where the LE contour of circular arc blends into the suction surface. Therefore, the applied turbulence model was considered adequate for the studies reported herein. 


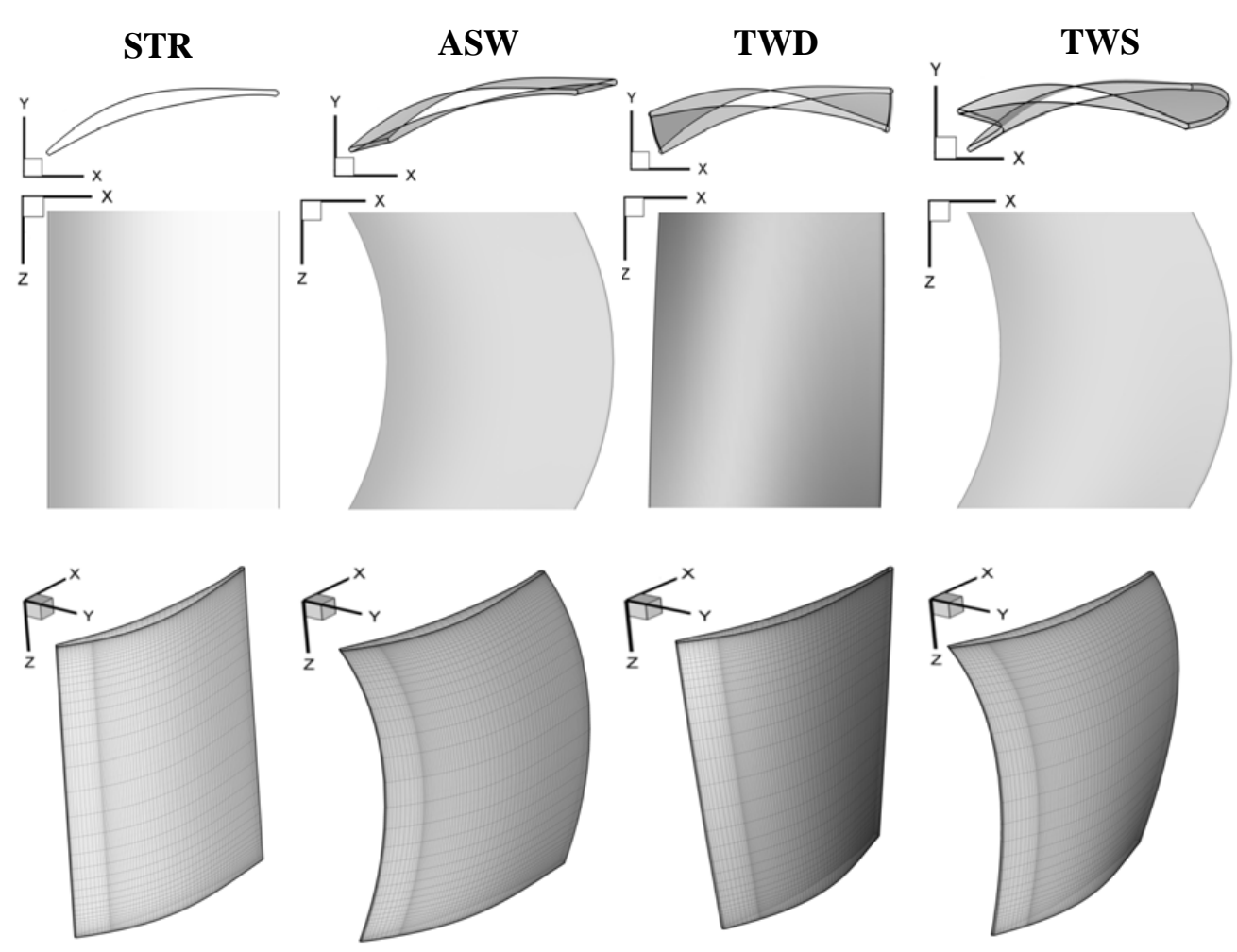

Fig. 2. Views of blades of case study

The following inflow turbulence conditions were set: inlet turbulence intensity of 0.03 , length scale of $0.12 \mathrm{~S}$. The modified turbulent viscosity ratio, the transported variable of the SpalartAllmaras model, was computed as the product of $(3 / 2)^{0.5}$ times the mean velocity, the turbulence intensity and the length scale.

The computational domain includes one blade passage (repeating itself periodically in order to compose an infinite blade row), with one blade located in the middle of the pitch (blade spacing). Utilising the features of the cascade configuration, boundary condition of periodicity has been applied. A zero diffusion flux condition has been used for all flow variables at the cascade outlet.

In a multi-step development process, a two-dimensional (2D) grid was first elaborated. The 2D computational domain of one blade passage, including the blade at mid-pitch, extends 1 chord upstream and 2 chords downstream of the blade, bounded by axial planes termed herein as "inlet" and "outlet" planes, respectively.

The 2D grid consists of approx. 16.000 quadrilateral cells. The expansion ratio, i.e. ratio of length of wall normal edges of neighbouring cells in the near-blade region has been set in a range of 1.12 to 1.15 . The thickness of the cell layer closest to the blade surface is in the range of $4 \cdot 10^{-5}$ to $7 \cdot 10^{-5} c$. The grid structure, grid sensitivity tests, cell skewness, aspect ratio, and wall $\mathrm{y}^{+}$values are reported in Rábai and Vad (2005)[14], and indicate an appropriate grid quality, according to the recommendations by Casey and Wintergerste [22].

For the STR and ASW bladings, and also for SWF [3] used in experimental validation, the three-dimensional (3D) grid structures were derived by extruding the $2 \mathrm{D}$ one along the stacking lines. 80 nodes have been used in the spanwise direction, resulting in a total number of approx. 1.200 .000 cells. The spanwise constant expansion ratio is approx. 1.2 , resulting in a symmetrically refined grid near the endwall boundaries. The spanwise extension of cells closest to the endwalls and at midspan is $5.5 \cdot 10^{-5} S$ and $0.087 S$, respectively. The STR and ASW grid structures were twisted and re-arranged for the TWD and TWS case studies, respectively.

Since Gbadebo et al. [1] found that the grid structure in the spanwise direction has the most influence on the 3D CFD computation of linear cascades, the 3D grid dependence studies focussed on the variation of grid along the span. It has been concluded in [15] that CFD resolution of aerodynamic properties related to the non-swept and swept blades and established on the basis of precise measurements is not masked by grid dependence.

The experimental data available in [21] and [3] on the same type of controlled diffusion blading offered a basis for experimental validation. The validation procedure is documented in [14] and [15], therefore only the most relevant conclusions are reported herein. Two cascades of experimental validation, denoted as STR (straight) and SWF (swept-forward), for which detailed measurement data were available in [3], were modelled with use of the reported CFD methodology. $C_{L}$ and $C_{D}$ were computed using the experimental as well as CFD data. The computations resolved both $C_{L}$ and $C_{D}$ near the endwalls within the range of experimental uncertainty $( \pm 1.0$ percent and \pm 4.0 percent, respectively). The effects of varying incidence angle on static pressure distribution were studied by CFD and were compared with the measurement data in [21]. It has been concluded, 

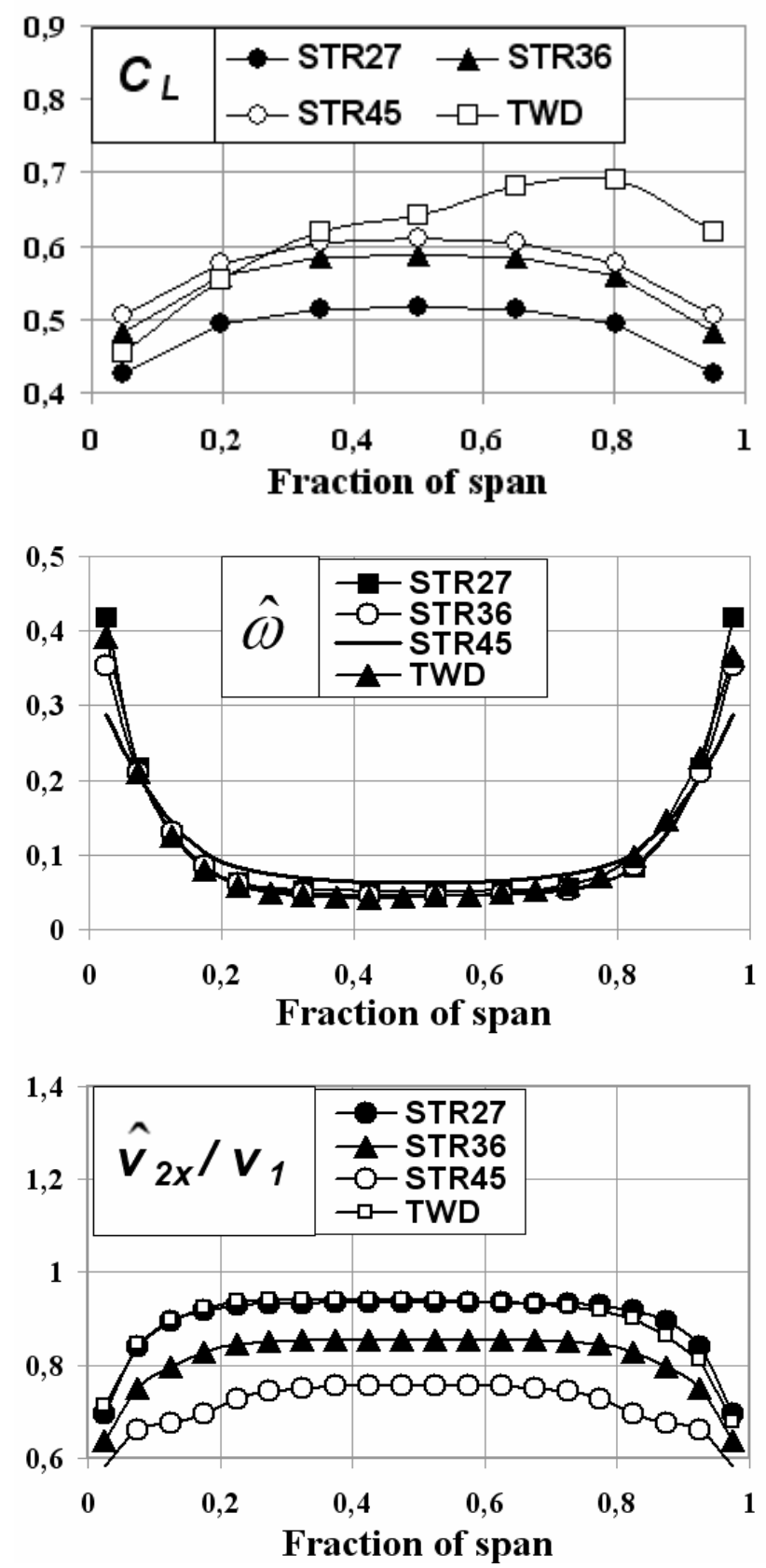

Fig. 3. Spanwise distribution of $C_{L}$, loss, axial velocity and discrepancies

that the CFD model resolves the measurement trends properly. Furthermore, the maximum lift-to-loss ratio was indicated by the measurements at the near-design inlet flow angle of $36 \mathrm{deg}$, and this value has also been properly represented by the computations.

\section{Results and discussion}

Based on the experimental validation, only the CFD-predicted trends exceeding the uncertainty of the experimental data used in the validation were considered as significant trends to be discussed herein. Only the most representative results are reported. In each case of non-dimensionalisation, $v_{1}$ denotes the velocity at the inlet at midspan.
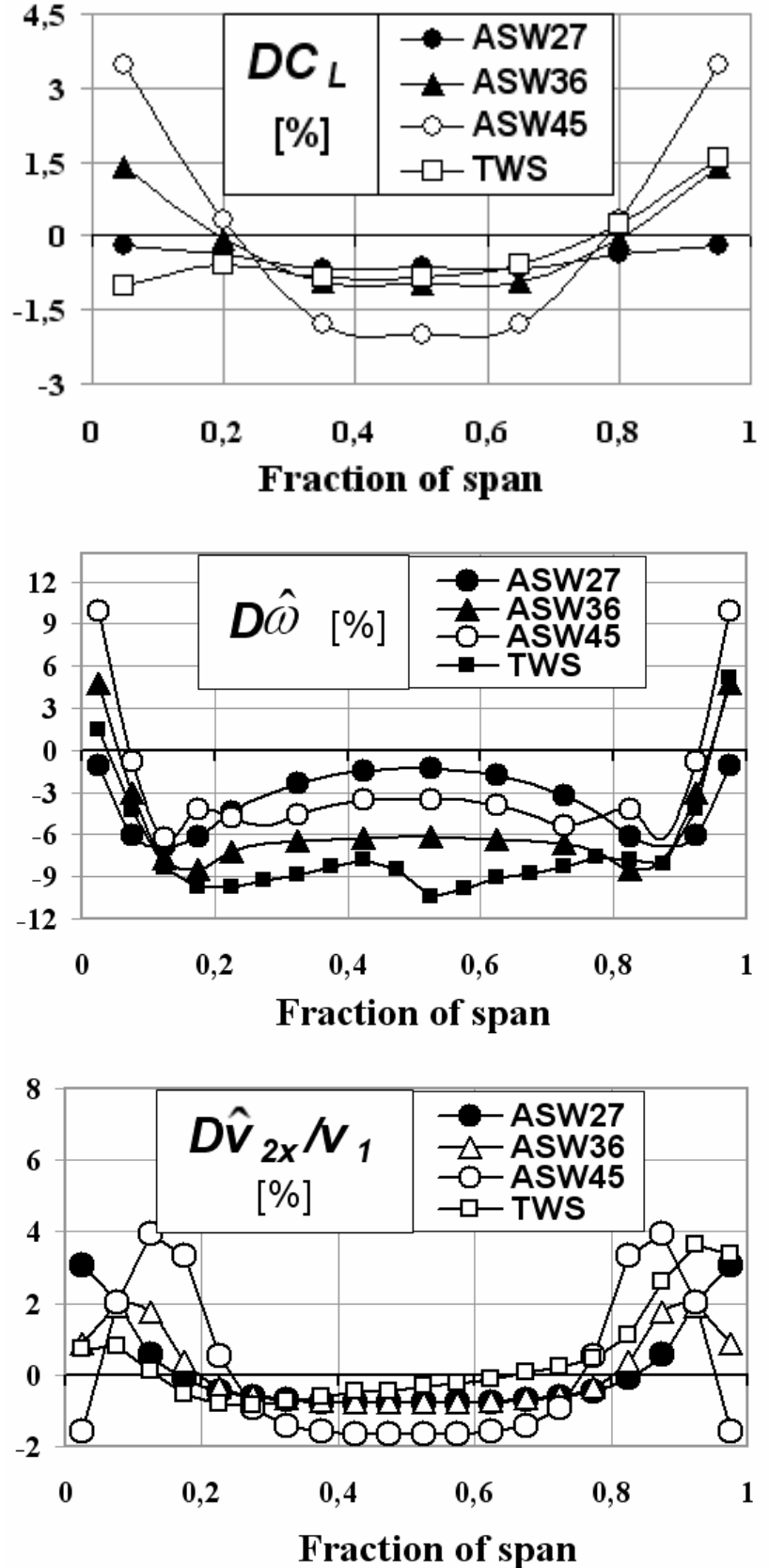

3.1 Tendencies along the span

The local total pressure loss coefficient has been introduced:

$$
\omega=\frac{p_{t 1}-p_{t}}{\rho v_{1}^{2} / 2}
$$

where $p_{t 1}$ is the total pressure at the inlet at midspan and $p_{t}$ is the local total pressure.

Traditional lift and drag coefficients are used even nowadays for characterisation of blade aerodynamics ([10, 13, 23] ). In a decelerating stationary cascade, the local drag and lift coefficients are related to the cascade losses and static pressure recovery, as can be pointed out on the basis of appropriate modification of discussion in [24]. In order to study the blade load, local lift coefficient data were calculated along the span. The lift coefficient of an elemental blade section of spanwise extension $d S$ 
is defined as follows:

$$
C_{L}=\frac{d F_{L}}{\rho d S c v_{\infty}^{2} / 2}
$$

where $d F_{L}$ is the elemental lift force acting on the blade section. As explained in [10], the lift force can be approached as the force normal to the chord for moderate angles of attack. Furthermore, based on [13], the normal force has been estimated as the difference of the mean static pressures between the PS and SS of the blade. The local static pressure coefficient has been introduced in the following manner:

$$
C_{p}=\frac{p-p_{1}}{\rho v_{1}^{2} / 2}
$$

Where $p$ is the local static pressure and $p_{1}$ is the static pressure at the inlet at midspan. Accepting here the approximation of $v_{\infty} \approx v_{1}$, the local $C_{L}$ has been calculated as the difference between the area-average of $C_{p}$ distributions over the PS and SS. This methodology for calculation of $C_{L}$ has already been accepted in [15].

Fig. 3 presents the spanwise distribution of lift coefficient, pitch-averaged total pressure loss coefficient and dimensionless pitch-averaged axial velocity for the unswept cases.

The presented loss and axial velocity data are related to $98 \%$ chord. For the swept cases, relative discrepancy of the investigated parameters has been introduced:

$$
D X_{\text {swept }}=\left(X_{\text {swept }}-X_{\text {non-swept }}\right) / X_{\text {non-swept }}
$$

where $X$ represents the investigated parameter and the subscripts "swept" and "non-swept" regard the swept (ASW, TWS) and non-swept (STR, TWD) cases, respectively.

Fig. 3 shows that higher incidence results in higher $C_{L}$ values in all cases. The variation of lift due to spanwise changing incidence of the twisted blading can also be observed. The lift on the high incidence region of the twisted blading is significantly higher than any of the non-twisted blades. This phenomenon will be explained later.

Positive sweep usually tends to unload the blade near the endwall (e.g. [13]). This trend was observed, although moderately, in the case of the untwisted blading at $27 \mathrm{deg}$ inlet flow angle and for the twisted blading near the low-incidence endwall (reduced $C_{L}$ ). The situation is just the opposite for the straight blading at 36 and $45 \mathrm{deg}$ inlet flow angles and for the twisted blading near the high-incidence endwall.

It can be seen in Fig. 3, especially for STR45 - ASW45, that the blade load is reduced in the near-midspan region due to sweep. The reduced blade load away from the endwalls of the arc-swept blades is attributed to the following: i) No stacking line blend points are present. By this means, the effect pointed out by [3, 9, 10], i.e. increased blade loading where the sweep blends into the straight section, has been eliminated. ii) The arc-swept blade sections away from the endwall still have considerable sweep. Disregarding endwall effects, sweep tends to lessen the lift [25]. The near-midspan reduction of lift due to sweep appears in measurements on bladings even of low aspect ratio [24].

Fig. 3 shows the effects of arc-sweep also on pitch-averaged total pressure loss coefficients. Sweep resulted in reduced losses for all cases at the region of approx. $10 \%$ to $90 \%$ span in all cases. The greatest loss reduction appears at the region of $10 \%$ to $30 \%$ span on both sides for all swept blades except TWS. Investigation of the limiting streamlines [1] on the blades (not presented herein) showed the suppression of the stall zone in the SS - endwall corner due to sweep, which explains the local loss reduction seen in Fig. 3. This effect of sweep is in accordance with the general view in the literature [11,13]. Furthermore, the reduction of the stall zone "liberates" the blade locally at 36 and $45 \mathrm{deg}$ incidences, thus higher endwall performance (lift) is achieved as seen in Fig. 3

The comparison of lift and loss data near the endwall of STR45 and at the high-incidence end of TWD (having incidence equal to that of STR45), denoted as TWD45, is as follows. At the "near-endwall" spanwise position, $C_{L S T R 45}=0.504$ and $C_{L T W D 45}=0.620$, and $\hat{\omega}_{S T R 45}=0.23$ and $\hat{\omega}_{T W D 45}=0.265$ were computed, thus higher load resulted in higher losses. As Fig. 3 suggests, further gain of lift can be achieved for the highincidence end of TWD if sweep is introduced: $C_{L T W D S}=0.629$ at the high-incidence blade end at the "near-endwall" location.

Sweep effects on pitch-averaged axial velocity distribution in Fig. 3 show that at near-endwalls sweep increases the axial velocity ("liberating" effect), whereas it is reduced at midspan. This results in a more uniform velocity distribution, which is favourable in multistage turbomachinery.

\subsection{Flow details}

In each studied case, near-endwall positive sweep was found to reduce the suction peak as well as unload and upload the nearLE and near-TE blade sections, respectively, resulting in a moderate adverse pressure gradient on the SS. For example, Fig. 4 presents the comparative $C_{p}$ diagrams for the untwisted blades at $27 \mathrm{deg}$ inlet flow angle. Since the phenomena due to sweep are less visible in the $C_{p}$ distributions, the dimensionless chordwise distribution of chordwise SS static pressure gradient $G$ has been introduced and also presented in Fig. 4

$$
G=\frac{\partial C_{p S S}}{\partial \text { (fraction of chord })}
$$

As Fig. 4 suggests, positive sweep results in the reduction of the suction peak (at points $G=0$ ) and in its shift toward the TE at low incidence. By unloading and uploading the near-LE and TE regions, respectively, positive sweep causes in general a reduction of the adverse pressure gradient $(G>0)$ over a considerable portion of the chord, even including the near-LE zone at high incidence.

The moderation of the adverse pressure gradient, due to positive sweep, detains the flow separation on the SS. This allows 


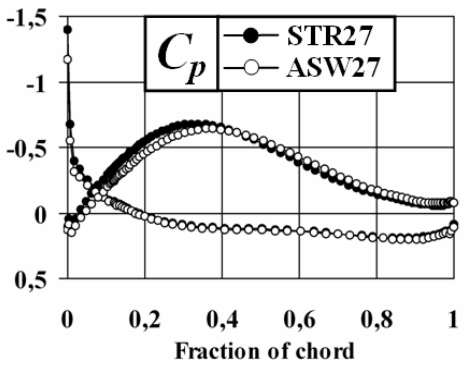

Fig. 4. $C_{p}$ and $G$ near the endwall

for a more intense depression on the SS, leading to improved lift near the endwall for ASW36, ASW45, and the high incidence end of TWS, as observed in Fig. 3 .

Fig. 5 presents the comparative diagram of surface static pressure distributions and chordwise static pressure gradients for these cases. It is observed that due to twist, the blade load is reduced at the LE and is increased toward the TE. As a result, the adverse pressure gradient $(G>0)$ is reduced up to 50 percent chord. These observations must be explained.

Based on a number of authors [3],[26],[13],[4], it is stated that positive dihedral (or "lean") causes the unloading of the nearendwall blade sections generally over the full passage. Just the opposite can be expected for negative dihedral. Due to the twist, the high-incidence end of TWD (TWD45) realises a combination of positive and negative dihedral along the chord: near the LE, the suction surface makes an obtuse angle with the endwall (positive "local dihedral"), whereas the angle between the suction surface and the endwall is acute near the TE (negative "local dihedral"). The positive and negative local dihedrals cause the unloading and uploading of the near-LE and near-TE blade sections, respectively. The result is a chordwise more uniform blade load distribution with a reduced adverse pressure gradient.

Fig. 6 showing the limiting streamlines on the endwalls of STR45, ASW45 and TWD45 demonstrates the benefits of the above. The streamline pattern for TWS45, not presented herein, is very similar to that for TWD45. The separation zones near the TE have been considerably reduced in TWD45. ASW45 also has reduced separation zones compared to STR45, due to the moderate adverse pressure gradients.

The chordwise more uniform blade load distribution for TWD45 appears to attenuate the cross-passage secondary flow transporting high-loss fluid toward the SS. This is suggested by Fig. 6, in which the limiting streamlines make a reduced angle with the suction surface in the twisted blading.

For STR27 and the low-incidence end of TWD - for which negative and positive dihedrals are present near the LE and TE, respectively -, one may expect just the opposite trends observed for STR45 and the high-incidence end of TWD (TWD45). However, the present CFD studies do not supply firm evidence for this, probably because of the weakness of the related effects due to the low incidence.

It must also be noted here that the literature does not provide

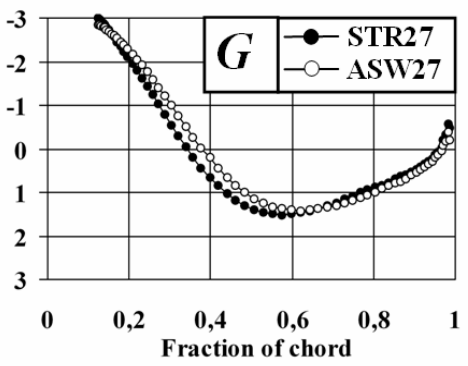

a firm guideline in the judgement of twist effects near the endwalls. On the basis of [26], it may be presumed that "localised blade twist" (increased stagger angle near the endwall) allows less flow through the near-endwall regime where increased loss can be generated, but causes non-uniform cascade outlet flow; and decreasing the stagger near the endwall may be beneficial from the aspect of a more uniform outlet flow. The latter consideration opposes the experiences by Wisler [27] that "end bend" with increased stagger near the end walls - as in the case of TWD at the low-incidence end - matches the blade inlet angle to the local flow direction in the endwall boundary layer, and accommodates the overturning near the endwall due to the secondary flows, leading to reduced endwall losses [28]. Further detailed studies are needed for a better understanding of the underlying physics of twist effects.
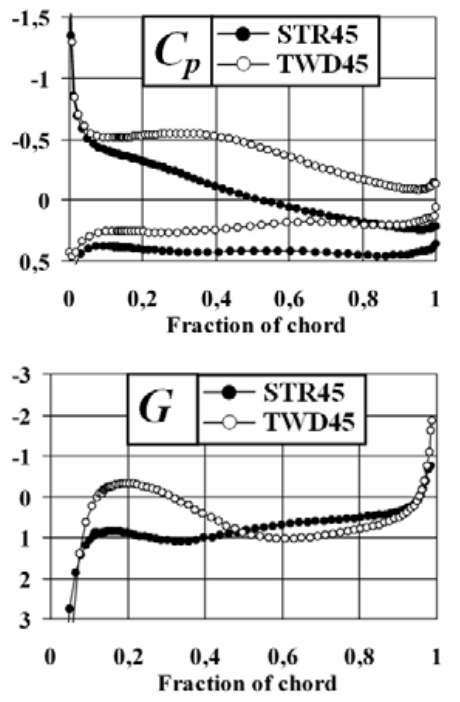

Fig. 5. $C_{p}$ and $G$ near the endwall

\section{Summary and conclusions}

Computational investigation has been carried out on the effects of sweep and twist in stationary linear cascades of controlled diffusion profile. Circular arc sweep has been applied to the datum cascade of straight cylindrical blades, i.e. spanwise constant curvature was prescribed for the stacking line. Positive sweep was applied near the endwalls, and the sweep angle distribution was symmetrical to the midspan plane. The straight and the arc-swept blades were studied at low, near-design, and 

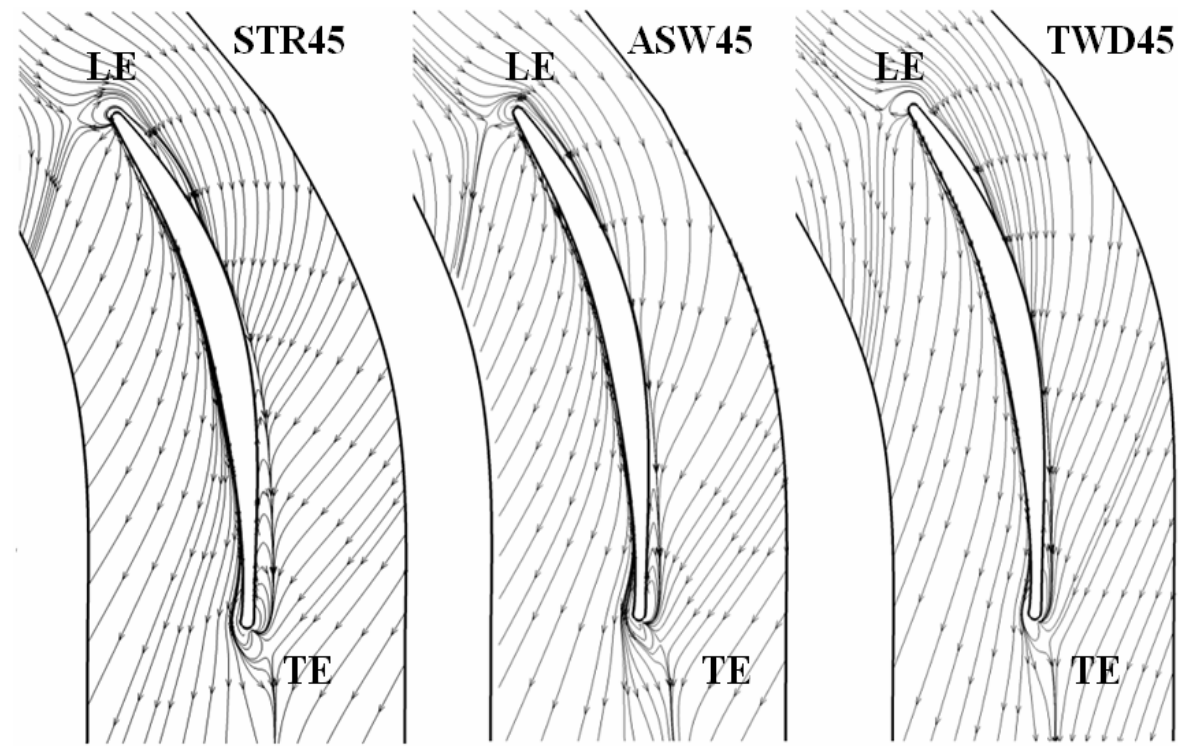

Fig. 6. Limiting streamlines on the endwall

high incidences of the straight blading. Twisted versions of the straight and the arc-swept blades were studied for spanwise constant inlet flow angle, resulting in a near-design incidence at midspan as well as the formerly mentioned low and high incidences near the endwalls. Preliminary studies were published in [29]. The results are summarised as follows.

1 Due to circular arc sweep, general reduction of the blade lift was observed, except for high-incidence near-endwall regions where the introduction of positive sweep helped in the moderation of flow separation, thus liberating the blade to perform higher lift.

2 Circular arc sweep reduced the loss in the region of $10 \%$ to $90 \%$ span for all incidences, by means of the moderation of corner stall.

3 If a blade is twisted near the endwall in such a way that the stagger angle decreases toward the endwall, positive and negative local dihedrals develop near the leading and trailing edges, respectively. This was found beneficial compared to the untwisted blade at high incidence, by ensuring a chordwise more uniform blade load and reduced adverse pressure gradient. The result is a reduced corner stall zone.

4 Arc-sweep was found to make the cascade outlet axial velocity profile more uniform at each incidence. This gives a potential for reducing the mixing loss, and preparing a more favourable inlet condition for the next blade row in multistage machinery.

\section{References}

1 Gbadebo S A, Cumpsty N A, Hynes T P, Three-dimensional separations in axial compressors., ASME J. Turbomachinery 127 (2005), 331-339.

2 Shang $\mathbf{E}$, Wang $\mathbf{Z} \mathbf{Q}$, Su J X, The experimental investigations on the compressor cascades with leaned and curved blade, 1993. ASME Paper No. 93GT-50.
3 Sasaki T, Breugelmans F, Comparison of sweep and dihedral effects on compressor cascade performance, ASME J. Turbomachinery 20 (1998), 454464.

4 Song Y, Zhao G, Chen F, Wang Z, Experimental study of sweep and dihedral effects on compressor cascade Performance, Proc. $6^{\text {th }}$ European Conference Turbomachinery Fluid Dynamics Thermodynamics, Lille, France, 2005, pp. 1-9.

5 Yamaguchi N, Tominaga T, Hattori S, Mitsuhashi T, Secondary-loss reduction by forward-skewing of axial compressor rotor blading, Proc. Yokohama International Gas Turbine Congress, Yokohama, Japan, 1991, pp. II.61II.68.

6 Corsini A, Rispoli F, Using sweep to extend the stall-free operational range in axial fan rotors, Proc. of IMechE, Part A - J. Power and Energy, 2004, pp. 129-139.

7 Wadia A R, Szucs P N, Crall D W, Inner workings of aerodynamic sweep, ASME J. Turbomachinery 120 (1998), 671-682.

8 Beiler M G, Carolus T H, Computation and measurement of the flow in axial flow fans with skewed blades, ASME J. Turbomachinery 121 (1999), 59-66.

9 Place J M M, Cumpsty N A, Discussion in Sasaki and Breugelmans, 1998. 10 Clemen C, Gümmer V, Goller M, Rohkamm H, Stark U, Saathoff H, Tip-aerodynamics of forward-swept rotor blades in a highly-loaded singlestage axial-flow low-speed compressor, 2004. Paper No. 027. (CD-ROM).

11 Friedrichs J, Baumgarten S, Kosyna G, Stark U, Effect of stator design on stator boundary layer flow in a highly loaded single-stage axial-flow lowspeed compressor, ASME J. Turbomachinery 123 (2001), 483-489.

12 High efficiency and low weight axial flow fan, 2002. Patent No. US 6,368,061 B1.

13 Clemen C, Stark U, Compressor blades with sweep and dihedral: a parameter study, Proc. $5^{\text {th }}$ European Conf. Turbomachinery Fluid Dynamics Thermodynamics, Prague, Czech Republic, 2003, pp. 151-161.

14 Rábai G, Vad J, Validation of a computational fluid dynamics method to be applied to linear cascades of twisted-swept blades, Periodica Polytechnica, Mechanical Eng. Series 49 (2005), no. 2, 163-180.

15 Vad J, Lohász M M, Rábai G, Rácz N, Tajti Á, Vassatis A, Corsini A, $A$ synthetic method for judging the validity of a CFD tool applied to axial flow cascades, Proc. $6^{\text {th }}$ European Conference Turbomachinery Fluid Dynamics Thermodynamics, Lille, France, 2005, pp. 10-19.

16 Habib M. A, Badr H. M, Said S. A. M, Hussaini I, Al-Bagawi J. J, On the development of deadleg criterion, ASME J. Fluids Engineering 127 (2005), 124-135. 
17 Sleiti A. K, Kapat J. S, Fluid flow and heat transfer in rotating curved duct at high rotation and density ratios, ASME J. Turbomachinery 127 (2005), 659-667.

18 Spalart P, Allmaras S, A one-equation turbulence model for aerodynamic flows (1992). AIAA Technical Report IAA-92-0439.

19 Gallimore S. J, Bolger J. J, Cumpsty N. A, Taylor M. J, Wright P. I, Place J. M. M, The use of sweep and dihedral in multistage axial flow compressor blading - Parts I and II., ASME J. Turbomachinery 124 (2002), 521-541.

20 Porreca L, Behr T, Schlienger J, Kalfas A. I, Abhari R. S, Ehrhard J, Janke E, Fluid dynamics and performance of partially and fully shrouded axial turbines, ASME J. Turbomachinery 127 (2005), 669-678.

21 Sanger N. L, Shreeve R. P, Comparison of the calculated and experimental cascade performance for controlled-diffusion compressor stator blading, ASME J. Turbomachinery 108 (1986), 42-50.

22 Casey M, Wintergerste T (eds.), Best practice guidelines, ERCOFTAC Special Interest Group on "Quality and Trust in Industrial CFD", Version 1.0, January 2000.

23 Horlock J. H, Denton J. D, A review of some early design practice using computational fluid dynamics and a current perspective, ASME J. Turbomachinery 127 (2005), 5-13.

24 Vad J, Kwedikha A. R. A, Jaberg H, Influence of blade sweep on the energetic behavior of axial flow turbomachinery rotors at design flow rate (2004). ASME Paper GT2004-53544.

25 Smith L H, Yeh H, Sweep and dihedral effects in axial-flow turbomachinery, ASME J. Basic Engineering (September 1963), 401-416.

26 Denton J D, Xu L, The exploitation of $3 D$ flow in turbomachinery design, Turbomachinery Blade Design Systems, Von Karman Institute, Belgium. Lecture Series, February 1999.

27 Wisler D C, Loss reduction in axial-flow compressors through low-speed model testing, ASME J. Engineering Gas Turbines Power 107 (1985), 354363.

28 Lakshminarayana B, Fluid dynamics and heat transfer of turbomachinery, John Wiley \& Sons, Inc., 1996.

29 Rábai G, Vad J, Lohász M M, Aerodynamic study on linear cascades of straight, arc-swept and twisted blades, Proc. $7^{\text {th }}$ European Conference Turbomachinery Fluid Dynamics Thermodynamics, Athens, Greece, 2007.

\section{Symbols}

$\alpha[\operatorname{deg}]$

flow angle (measured from the axial direction)

$C[-] \quad$ force coefficient (lift, drag)

$C_{p}[-] \quad$ static pressure coefficient

$c[m] \quad$ blade chord

$D[\%] \quad$ relative discrepancy (between swept and nonswept cases)

$d F[N] \quad$ elemental blade force

$G[-] \quad$ dimensionless chordwise pressure gradient on the suction side

$\gamma[\mathrm{deg}] \quad$ blade stagger angle (meas. from the ax. direction)

$p[\mathrm{~Pa}] \quad$ local static pressure

$p_{t}[\mathrm{~Pa}] \quad$ local total pressure

$\Delta p[P a] \quad$ static pressure rise

$\rho\left[\mathrm{kg} / \mathrm{m}^{3}\right] \quad$ fluid density

$S[m] \quad$ blade span (height)

$s[\mathrm{~m}] \quad$ blade spacing (pitch)

$v[\mathrm{~m} / \mathrm{s}] \quad$ fluid velocity

$x, y, z[m]$ axial (normal to the pitchwise direction), pitchwise, and spanwise coordinates

$y^{+}[-] \quad$ wall normal cell size (in wall units)

$\omega[-] \quad$ local total pressure loss coefficient

\section{Subsctipts and superscripts}

pitchwise mass-averaged value

$\infty \quad$ free-stream characteristics

1 cascade inlet

2 cascade outlet

D drag

L lift

id ideal (inviscid)

$x, y \quad$ axial, pitchwise 